\title{
Editorial
}

\section{Pensando a Goethe}

Resumen: ¿hay que seguir leyendo a Goethe? La germanística tradicional lo sigue prescribiendo. Sin embargo, esa imposición produce antipatía. Eso unido a su conservadurismo político, a su resistencia a las novedades estéticas y a su visión disparatada de la ciencia crean una imagen muy negativa del escritor. Sin embargo, esos motivos de animadversión deben ser matizados. Su conservadurismo es explicable en claves biográficas (un hijo de la burguesía entre nobles). Él no pretendía ser estéticamente innovador, pero muchas de sus obras superaron los límites convencionales de los géneros literarios. Por otra parte, su concepción de la ciencia puede ser entendida como una crítica ecologista al paradigma dominante de su época.

Palabras clave: Goethe, rechazo, política, innovación, ecología, acción.

\section{Thinking over Goethe}

\begin{abstract}
Goethe? The traditional mainstream in German Studies prescribes it. Nevertheless, such imposition provokes antipathy. This, together with his political conservatism, his resistance to aesthetic novelties and his crazy vision of science, create a very negative image of the writer. But, these motives of animosity must be nuanced. Its conservatism is understandable in biographical keys (he was a son of the bourgeoisie among aristocrats). He did not pretend to be aesthetically innovative, but many of his works overcame the conventional limits of literary genres. Moreover, his conception of science can be understood as an ecological critic to the dominant paradigm of his time.
\end{abstract}

Keywords: Goethe, rejection, conservatism, aesthetical innovation, ecology, action. 


\title{
Pensando a Goethe
}

¿Por qué seguir leyendo a Goethe? Para el germanista, al menos oficialmente, no hay lugar a esa pregunta, pues se topa ante el autor en lengua alemana más centralmente ubicado en aquello que Harold Bloom denominara El canon occidental (Bloom, 1995, p. 216). Sin embargo, tampoco puede negarse que esa condición de "indiscutible" a veces irrita, y que no son pocos los que ven en Goethe un personaje olímpico, áulico, frío y displicente.

\begin{abstract}
Nada de lo que es lo es radicalmente y con plenitud: es un ministro que no es en serio un ministro; un régisseur que detesta el teatro, que es propiamente un régisseur; un naturalista que no acaba de serlo, y ya que irremediablemente, por especialísimo decreto divino, es un poeta, obligará a reclutar soldados cabalgando un caballo oficial que se llamaba "Poesía" (Ortega y Gasset, 1983, pp. 36-37).
\end{abstract}

Hay al menos cuatro focos que concentran esa antipatía. El primero, ya aludido: el de la consideración del autor como una figura de consabida importancia y cuyo estudio ha de ser forzoso. Tal vez Novalis o Kleist o Heine sean prescindibles, pero Goethe no, o eso es lo que indican los manuales de Historia de la Literatura. En ellos, tanto en los ya añejos como en los recientes, para describirlo se suceden los elogios: "mayor maestro de vida que Europa ha conocido" (Martini, 1964, p. 226), clásico (Baumann, 1996, p. 101), "armonía entre autor, forma y contenido" (Hernández y Maldonado, 2003, p. 96). Sobre este aspecto de la necesidad de tener en cuenta a Goethe volveremos al final, pues tiene que ver con la valía o no de su obra literaria. Los otros tres núcleos de antipatía o animadversión son su conservadurismo político, su recelo frente a las novedades estéticas y su enfoque disparatado de la ciencia.

Ya hemos señalado que el segundo motivo de antipatía tiene que ver con la actitud políticamente acomodaticia, cuando no reaccionaria. Sus detractores señalan que habiendo obtenido su licenciatura en Derecho y habiendo triunfado literariamente con Werther, un hijo de la burguesía, no hizo asco alguno a convertirse primero en Ministro luego en Jefe de Gabinete del Archiduque de Sachsen-Weimar. O dicho de otro modo un hombre nacido para ser libre, se convirtió en un lacayo. El juicio es duro, y no del todo muy fundado. Si Goethe se hubiera quedado en Wetzlar o en Frankfurt am Main, difícilmente habría llegado a ser quien fue. Sí, tal vez Goethe podría haber sido un paladín del Tercer Estamento dedicándose a la abogacía, pero marchar a la Corte de Carlos Augusto, le permitió dedicarse a la poesía, a la ciencia y al pensamiento de un modo más holgado y menos agobiado que si hubiera tenido la vida y el día a día de un jurista profesional. ¿A costa de la coherencia y el compromiso con sus orígenes?, ¿claudicando para dejar de ser un burgués y convertirse en un noble de nuevo cuño? ¿Para dejar de ser Johann Wolfgang Goethe y pasar a ser Johann Wolfgang 
von Goethe? Tal vez pueda reprochársele por eso, pero Goethe comprendió mejor que nadie que el tiempo de la burguesía llegaría, pero que a la nobleza todavía le quedaba tiempo por subsistir, y que, sin aceptar temporalmente esa servidumbre, no habría podido comprender la realidad política de su época. Al hilo de ello, y, para comprender la clarividencia que tuvo el poeta atendamos a la reflexión de Benjamin en su artículo "Goethe", para la Enciclopedia Soviética.

La burguesía alemana estaba lejos de ser lo suficientemente fuerte como para sostener un quehacer literario extenso por sus propios medios. La consecuencia de aquella situación fue que la literatura siguió dependiendo del feudalismo aun cuando la simpatía del literato estuviera del lado de la burguesía (Benjamin,1996, p. 43).

Sin su presencia en un microestado no podría haberse dedicado a las obras públicas, la restauración artística, la escenografía y dirección teatral, la mineralogía e ingeniería de minas, la botánica y la ingeniería de montes, la mineralogía y la embriología, la óptica y la teoría de los colores. Y, por añadidura, no podría haber ayudado a amigos como Meyer, o, sobre todo, como su querido y ponderado Schiller. Es cierto que esa posición de burgués entre nobles tuvo siempre que refrendarse mediante una especie de certificados de buena conducta, y que su proceder en el Estado archiducal siempre fue mirado con lupa. Sin duda, esa actitud nos parece mucho menos atractiva que la de un rebelde, pero no fue entreguismo ni caída en lo acomodaticio. Su trayectoria en Weimar estuvo guiada por un sentido de la realidad que le permitió realizarse no sólo como intelectual y poeta, sino como ser humano completo. Además, y por añadidura, su realización posibilitó que otros amigos suyos, también hijos de la burguesía, pudieran llegar a ser lo que fueron.

Sin salir de lo político, también se le reprocha a Goethe, su postura ante la Revolución Francesa. De nuevo la dureza es extrema. La Revolución Francesa fue un acontecimiento histórico que puso la soberanía nacional al pie de las constituciones y los sistemas políticos, que hizo de los derechos del hombre ciudadano fundamento de estos sistemas y que convirtió esta soberanía en principio a salvaguardar. Ahora bien, que ese fuera el balance de la Revolución Francesa no quiere decir que el camino que recorrió no fuera pedregoso y lleno de violencia. Sin ir más lejos, Goethe fue testigo del momento de mayor aspereza: el Terror, la guillotina y Robespierre. No es extraño pues que Goethe (al igual que Schiller en sus Cartas para la educación estética del hombre) desarrollara ese impulso tan propio de la "intelligentsia" alemana, según el cual, no puede haber auténtica liberación hasta que el pueblo esté formado para ella.

Los adversarios de Goethe se aferran a su famosa frase "Prefiero la injusticia al desorden". Frase poco afortunada y que, como se sabe, Goethe empleó cuando evitó que no se linchara a un francés incendiario que pretendía quemar la Catedral 
de Mainz, dando a entender que, aunque fuera justo matarlo, era preferible que se mantuviera la orden de que los revolucionarios franceses derrotados pudieran retirarse pacíficamente. Mas, parafraseando a Sartre, ¿es posible evitar tener las manos sucias en política? Henry David Thoreau defendió la desobediencia civil y se negó a pagar impuestos. Si bien el único castigo que sufrió por ello fue pasar una noche en el calabozo, pues a la mañana siguiente pagaron su fianza. Vladimir Illitch Ulianov, Lenin, piedra angular de la Revolución de 1917, llegó a la Estación Finlandia de San Petersburgo después de haber sido protegido y sufragado por el servicio secreto de la Alemania Guillermina que quería minar el poder de la Rusia zarista. Mohandas Kachamdar, más conocido como Mahatma Gandhi, promovió la teoría y la práctica de la resistencia pasiva y la no violencia, pero la Independencia de la India, de la que fue principal promotor, se saldó con millones de muertos en enfrentamientos entre hindúes y musulmanes y en las Guerras Indo-pakistaníes.

Y siguiendo con lo político, ese certificado de buena conducta que Goethe estuvo obligado a obtener le granjeó mucho dolor. Fundamentalmente el dolor de no poder amar a quien quería y admiraba: a Charlotte von Stein. El Archiducado de Weimar no estaba preparado para aceptar la relación sentimental de una mujer de la nobleza, casada con el cuadrillero mayor de Carlos Augusto, con un escritor, es cierto, sí, con un escritor de éxito, pero plebeyo. Como señala Judith Butler, "lo privado es público", y lo privado no pudo hacerse público en el amor de Goethe y Lotte. Una de las lecturas más habituales de Las penas del joven Werther afirma que Goethe "mató" a Werther para poder sobrevivir él, que, con el suicidio de ese personaje malhadado, Goethe exorcizó de su corazón su pasión de Wetzlar, Charlotte Buff. Ella, como la Lotte de Werther, prefirió a un abogado con firme vocación profesional por el derecho, que a un jurista incidental como Goethe. Sin embargo, con el destino no se puede jugar por mucho tiempo. Ya en Weimar, Goethe no pudo poner en marcha otra vez el recurso de la ficción y pasar de enamorado real a enamorado literario. Ya no pudo trocar persona por personaje. El amor por Charlotte von Stein y la imposibilidad de vivirlo lo llenaron de una pesadumbre que en esta ocasión no fue salvable por el recurso a la fabulación. Por eso, es injusta la acusación de que Goethe fuera un personaje olímpico, áulico, frío y displicente. De que fuera alguien capaz de vivir en la indiferencia respecto al calor humano. Goethe sufrió y mucho por intentar vivir en un mundo ajeno a aquel en que nació, y su tragedia en este caso fue no poder amar a quien amó. Para paliar la "herida Stein", hubo de viajar a Italia, hubo de descubrir el amor carnal y hubo de vivir esa sensualidad conquistada con Christiane Vulpius. ¿La herida quedó restañada? La acción, pues como tradujo Fausto a San Juan "Am Anfang war die Tat" ("En el principio fue la acción" en lugar de "En el principio fue la Palabra"), la fue cerrando.

Por otra parte, nuevas investigaciones sobre el autor revelan que su valoración como alguien conservador y acomodaticio es matizable, si no discutible. No 
fueron solo ventajas individuales las que lo llevaron a Weimar y no fue un entorno confortante lo que lo retuvo allí. De hecho, la comodidad y la conveniencia le habrían aconsejado más haberse quedado en Frankfurt. Su familia tenía una buena posición económica y tradición de juristas entre sus miembros y él a los veintiséis años era doctor en Derecho. Con la base de sustento de la abogacía podría haberse permitido ser un escritor a tiempo parcial (Krippendorff, 1988, p. 22). Sin embargo, tal vez la clave esté en que no le bastaba con ser sólo un poeta. Weimar fue para él un banco de pruebas para una buena gobernanza alternativa a la política de las potencias estatales predominante en su tiempo. Política por la que sentía una aversión fundamentada en los abusos a los que conducía. Eckermann recoge el 17 de marzo de 1830 un momento de visceralidad de Goethe especialmente ilustrativo de esa aversión. Lord Bristol le había mostrado al escritor su juicio negativo respecto Werther, al que valoraba como un libro inmoral y condenable. A ello el poeta le espetó:

Halt [...] Wenn Ihr so über den armen Werther redet, welchen Ton wollt Ihr gegen die Großen dieser Erde anstimmen, die durch einen Federzug hunderttausend Menschen in Feld schicken, wovon achtzigtausend sich töten und sich gegenseitig zu Mord, Brand un Plünderung anreizen. Ihr danket Gott nach solchen Greuel und singet ein Tedeum darauf (Cit.sg. Krippendorff, 1988, p. 89).

Y hay un aspecto más, que no queremos dejar pasar: la cuestión de género. La literatura fue para Goethe una herramienta de análisis de lo humano, que lo ayuda a liberarse de los estereotipos propios de la antropología dominante (Pfotenhauer, 1987, pp. 1-28). Esa antropología inevitablemente sexista. En muchos momentos de su obra, Goethe intenta contestar a la cuestión de ien qué medida hombres y mujeres están en condiciones de entender mutuamente sus formas de percibir? (Herwig, 1997, p. 29).

En los dos últimos versos de Fausto (II, 12110-12111) leemos "Das EwigWeibliche zieht uns hinan" (Lo eterno femenino nos hace avanzar). Esta es una visión ambigua de lo femenino. Parece que el varón, aludido en esa primera persona del plural "uns" (nos), es sujeto, es la instancia activa que avanza. Lo femenino, por el contrario, se presenta como lo inacabado y lo potencial. Aunque lo que dinamiza siempre es más sugerente que lo estimulado, la polaridad propuesta por Goethe no parece más que otra variante de patriarcal paternalismo. Sin embargo, merece la pena considerar esa función motora de lo femenino.

Tomando como punto de referencia Wilhelm Meisters Wanderjahre encontramos muchos relatos intercalados que tienen por denominador temático común el amor y cuyo sentido nunca es sencillo ni evidente a una primera lectura (Schlechta, 1985, p. 65). Y en esos relatos, vemos a mujeres asertivas y con iniciativa propia. 
De entre todas estas narraciones destaca "Das nussbraune Mädchen", la más firme adhesión de Goethe a la emancipación femenina. El título encabeza un capítulo de la obra, lo que resulta engañoso, ya que lo relatado desemboca en la novela. Desde sus primeras líneas la narración liga la discriminación de género a la desigualdad y la injusticia económicas. Con objeto de financiar un viaje por el extranjero a Lenardo, su tío decide cobrarse deudas de sus aparceros. Hay uno de ellos, el padre de Nacodina, la muchacha de piel de nuez, que no puede enfrentar el pago y es expulsado de su explotación. La muchacha recurre a Lenardo para que medie ante el tío en favor de su padre. A pesar de que lo promete, el noble no lo hace, y pasado un tiempo incuba en su interior mala conciencia y preocupación por la suerte de Nacodina. Cuando la encuentra ya no es la desvalida joven que él abandonó a su suerte. Ahora, con el nombre de Susana, se ha convertido en una solvente profesional de la industria textil. Por otra parte, no se aviene al matrimonio que Lenardo le ofrece para compensarla por sus sufrimientos. Para preservar su independencia, Nacodina-Susana acaba convirtiéndose en bibliotecaria y asistente de otro personaje de la novela, Macaria.

El tercer motivo de ataque contra Goethe es su posición estética, más orientada al pasado que a la innovación, o quizás más anclada en el clasicismo que abierta a las nuevas tendencias. En literatura, rechazó a los románticos y a "Neues Deutschland". En pintura y artes plásticas, osciló entre el medievalismo germanófilo y el clasicismo arqueológico, pero siempre denostó el falaz revival de la Edad Media propugnado por los nazarenos. En música, admirando a Haydn y Mozart, no comprendió a Schumann a Schubert ni a Beethoven. Mas, ¿es la posición estética aquello que debemos juzgar para apreciar la calidad de un autor? Es cierto que hay autores que han tenido una enorme penetración para comprender, no sólo las corrientes estéticas contemporáneas, sino también para intuir por dónde éstas seguirían desarrollándose. Y desde este punto de vista nos parece absolutamente admirable, por ejemplo, Diderot o también a su modo Baudelaire. Sin embargo, hay quienes han destacado por llevar a cabo tanto el aprovechamiento al máximo de unas tendencias como por el avizorar lo nuevo en la propia creación. Goethe lleva el "Sturm und Drang" al máximo de sus posibilidades con Werther.

Goethe agota el modelo clasicista con una enorme elegancia en Ifigenia en Tauris. Goethe lleva la tragedia a un grado de maestría y acabamiento geniales en Las afinidades electivas. Goethe hace de la novela un camino de autoconocimiento y de reconocimiento de las circunstancias externas en Los años de aprendizaje y Los años itinerantes de Wilhelm Meister. Goethe crea una obra única, en un género literario complicadísimo, el poema dramático, con el Fausto. Y todo eso nos lleva a preguntarnos: ¿qué es más importante, ser innovador desde dentro y en la creación literaria o ser capaz de detectar la auténtica innovación en las producciones ajenas? Incluso desde una perspectiva como la mía, que, desde la 
estética y la teoría de las artes, intenta poner de relieve lo importante que es la comprensión de lo creativo, no puede negarse que siempre será más importante la creación misma, que la comprensión de esa creación.

A Goethe, por otra parte, se le considera científicamente disparatado. Newton había propuesto una teoría del color, según la cual este es al resultado de la absorción de los rayos de luz por los cuerpos. A ello Goethe repuso que el color era el resultado de las diversas gradaciones obtenidas por la oposición entre la luz y la oscuridad. Realmente la teoría goethiana, más bien esotérica y poética, que propiamente científica tiene valor como rechazo de una visión escrutadora y fría de la realidad nacida con la Revolución Científica originada con Copérnico. Una ciencia no interesada en abrazar la realidad y penetrarla, sino en medirla y controlarla. Bien sabido es que Copérnico no pretendió decir que el centro del Universo conocido en su época fuera el sol, sino que si se aceptaba la hipótesis de que así fuera, los movimientos de los planetas serían más precisa y sencillamente descriptibles. Goethe rechaza ese proceder frío que se aparta de la realidad para así comprenderla. En definitiva, rechaza las tornas que tomó la ciencia cuando advino aquello que Heidegger llamó la "época de la imagen del mundo".

¿Por qué seguir leyendo a Goethe? Porque su vida y su obra son un modelo de encarar y comprender la existencia. Con su adaptabilidad al ajeno Weimar, Goethe nos enseñó que un ser humano ha de ser capaz de aprovechar las oportunidades que da la vida para realizarse, y ser fiel a esa realización de modo tesonero, tenaz e inteligente. Y así ser poeta, hombre de Estado, restaurador artístico, escenógrafo, director teatral, científico, y, ante todo, buen amigo. Por eso sus obras autobiográficas Vida y poesía y su entrevista con Eckermann en Conversaciones con Goethe son un auténtico cuaderno de bitácora de un hombre tal vez más afortunado que la media, pero con coraje y voluntad para ser generoso y presto con ese destino afortunado. El amor frustrado por Charlotte von Stein le hizo ver que el único modo de acabar con lo trágico es cortar el nudo gordiano con la espada, y no intentar deshacerlo. El amor fallido por la Stein fue el punto de inflexión para vencer, si no a lo trágico, sí al dominio de lo trágico sobre un espíritu individual. Para él lo trágico, equivalente a lo fatal e inevitable, podía ser eludido cambiando el círculo y el medio de desarrollo de la vida. La tragedia no, pero sí sus efectos podían quedar anulados mediante el paso del yo al nosotros. El Doctor Fausto corta el nudo gordiano, cuando después de salir de su enmohecido gabinete y recorrer mundo sólo pensando en el propio placer y experiencia, se da cuenta de que lo importante son proyectos colectivos y solidarios para, enfrentándose a la naturaleza, hacer de la Tierra un lugar más habitable para el ser humano. Se da cuenta de que sólo hay algo que puede hacer sentir el deseo de que se pare el tiempo: que un pueblo sometido a la presión se una para vencerla. Wilhelm Meister corta el nudo gordiano, cuando descubre que su vocación artística y teatral no es auténtica, sino tan sólo un reflejo de un egotismo 
introspectivo y estéril. Entonces, sabe que el sentido de su vida es dedicarse a servir a los demás como médico y a apoyar a la Sociedad de la Torre en la formación de colonias en esa nueva tierra, América, en la que la agotada Europa encontrará alivio para su superpoblación, para su galopante pobreza y para sus diferencias estamentales. Siendo éstas, paliadas por la puesta del contador a cero que supone esta emigración. La propuesta de Fausto y de Wilhelm Meister es la misma: acabar con la tragedia desplazando la realidad hacia una esfera en la que lo compulsivo, lo fatal y lo necesario no sean la murria introspectiva, la autocompasión y el lamento por lo que no puede o no pudo ser. Un desplazamiento a una esfera en la que lo compulsivo, lo fatal y lo necesario sea hacer y actuar, porque en ello va la vida de todos, que es la que sostiene la vida de cada uno. Sólo una esfera así es capaz de lograr un pueblo libre en una tierra libre. Como decía Esquilo en Euménides, un pueblo capaz de "odiar con el mismo corazón". Al fin y al cabo: en el principio fue la acción.

Miguel Salmerón Infante

Universidad Autónoma de Madrid Correo electrónico: miguel.salmeron@uam.es

\section{Referencias}

Baumann, B. (1996). Deutsche Literatur in Epochen. Ismaning: Max Hueber Verlag.

Benjamin, W. (1996). Goethe. Artículo enciclopédico. Dos ensayos sobre Goethe (pp. 137-190). Barcelona: Gedisa.

Bloom, H. (2002). El canon occidental. Barcelona: Anagrama.

Hernández, I. y Maldonado, M. (2003). Literatura alemana. Épocas y movimientos desde los orígenes a nuestros días. Madrid: Alianza.

Herwig, H. (1997). Wilhelm Meisters Wanderjahre. Geschlechterdifferenz. Sozialer Wandel. Historische Anthropologie. Tübingen-Basel: Francke.

Krippendorff, E. (1998). Wie die Großen mit den Menschen spielen. Versuch über Goethes Politik. Frankfurt am Main: Suhrkamp.

Martini, F. (1964). Historia de la literatura alemana. Barcelona: Labor.

Ortega y Gasset, J. (1983). Pidiendo un Goethe desde dentro. Goethe-Dilthey.

Madrid: Revista de occidente-Alianza Editorial. 
Pfotenhauer, H. (1987). Literarische Anthropologie. Selbstbiographien und ihre Geschichte-am Leifaden des Leibes. Stuttgart: Metzler.

Schlechta, K. (1985). Goethes Wilhelm Meister. Frankfurt am Maim: Suhrkamp. 